\title{
The Story Behind the Numbers: Lessons Learned from the Integration of Monitoring Resources in Addressing an ISS Water Quality Anomaly
}

\author{
Torin McCoy ${ }^{1}$, Stephanie Flint ${ }^{2}$ \\ NASA Johnson Space Center, Houston, Texas, 77058 \\ John Straub II ${ }^{3}$, Dan Gazda ${ }^{4}$, John Schultz ${ }^{5}$ \\ Wyle Laboratories, Houston, Texas, 77058
}

\begin{abstract}
Beginning in June of 2010 an environmental mystery was unfolding on the International Space Station (ISS). The U.S. Water Processor Assembly (WPA) began to produce water with increasing levels of total organic carbon (TOC). A surprisingly consistent upward TOC trend was observed through weekly in-flight total organic carbon analyzer (TOCA) monitoring. As TOC is a general organics indicator, return of water archive samples was needed to make better-informed crew health decisions and to aid in WPA troubleshooting. TOCA-measured TOC was more than halfway to its health-based screening limit before archive samples could be returned on Soyuz 22 and analyzed.
\end{abstract}

Although TOC was confirmed to be elevated, somewhat surprisingly, none of the typical target compounds were the source. After some solid detective work, it was confirmed that the TOC was associated with a compound known as dimethylsilanediol (DMSD). DMSD is believed to be a breakdown product of siliconcontaining compounds present on ISS. A toxicological limit was set for DMSD and a forward plan developed for operations given this new understanding of the source of the TOC. This required extensive coordination with ISS stakeholders and innovative use of available in-flight and archive monitoring resources. Behind the numbers and scientific detail surrounding this anomaly, there exists a compelling story of multi-disciplinary awareness, teamwork, and important environmental lessons learned.

\section{Nomenclature}

$\begin{array}{ll}\text { DMSD } & =\text { dimethylsilanediol } \\ \text { ECLSS } & =\text { environmental control and life support system } \\ \text { ISS } & =\text { International Space Station } \\ \text { JSC } & =\text { Johnson Space Center } \\ \text { MSFC } & =\text { Marshall Space Flight Center } \\ \text { PPB } & =\text { parts per billion } \\ \text { TOC } & =\text { total organic carbon } \\ \text { TOCA } & =\text { total organic carbon analyzer } \\ \text { WAFAL } & =\text { Water and Food Analytical Laboratory } \\ W P A & =\text { water processor assembly }\end{array}$

\section{Introduction}

Tn some ways, the challenges that unfolded in June-November of 2010 represented a "perfect storm" for the 1 conscientious scientists and engineers charged with protecting crew health on-board the International Space

\footnotetext{
${ }^{1}$ Environmental Operations Lead, Space Life Sciences Directorate/SF23, NASA Johnson Space Center, Houston, Texas, 77058

${ }^{2}$ EHS Integration, Space Life Sciences Directorate/SF23, NASA Johnson Space Center, Houston, Texas, 77058

${ }^{3}$ Senior Engineer, Water and Food Analytical Laboratory, Wyle Laboratories, Houston Texas 77058

${ }^{4}$ Senior Scientist, Water and Food Analytical Laboratory, Wyle Laboratories, Houston Texas 77058

${ }^{5}$ Water and Food Analytical Laboratory Manager, Wyle Laboratories, Houston Texas 77058
} 
Station (ISS). In-flight monitoring was clearly indicating a steadily-rising chemical pollutant in the potable water produced by the U.S. Water Processor Assembly (WPA). There was no longer a concern as to whether the trend was real or not; the questions at hand were "What is causing it?", "Does it pose a health risk?", and "How can we mitigate it?". But to effectively answer these questions, one needed to first know the identity of the chemical, and several uncertain months and many unbridgeable miles still waited ahead of that identification that could only be enabled by ground analysis of returned archive water samples.

For all those involved, these were clearly challenging times. Of course, it is said that with every challenge there are also opportunities to expand knowledge, to test preparedness, to erase misconceptions, and to prepare for the future. This paper is intended to highlight and discuss those opportunities afforded by the events related to the unexpected appearance and disappearance of a chemical pollutant in U.S. potable water on-board the ISS in 2010. One reason the story is worth telling is that it highlights the practical challenges involved in integration of environmental monitoring tools in decision making within the current spaceflight operational paradigm. While technical events and findings are discussed, there is a focus on lessons learned. This paper highlights existing strengths, warns of potential vulnerabilities, and attempts to tell the richer and more challenging story that exists beyond the black-andwhite world of data points, fault trees, and response action plans.

\section{Event Description}

\section{A. Background}

On-orbit checkout of the U.S. Water Processor Assembly (WPA) was completed in 2008, which allowed for the treatment and recycling of urine distillate and ISS humidity condensate as potable water. This was a critical ISS milestone, as the recovered water was essential to sustain 6 crew operations. Despite the advanced treatment technologies that were designed into WPA, potential chemical and microbial risks associated with consumption of recycled water remain. For chemical constituents, those residual risks are, to a large degree, mitigated through environmental monitoring and analysis.

Environmental monitoring on ISS consists of both: (A) ground laboratory analysis of archive water samples returned on Shuttle or Soyuz vehicles ${ }^{1}$, and (B) in-flight monitoring technologies (Figure 1). JSC Water and Food Analytical Laboratory (WAFAL) scientists nominally arrange for monthly archive potable water samples to be collected from the WPA. The return of these $500-1000 \mathrm{~mL}$ samples depends on the schedule of Shuttle or Soyuz visitations to ISS, and whether there is available down mass.

The primary in-flight water monitoring technique is the total organic carbon analyzer (TOCA) ${ }^{2}$. Total organic carbon (TOC) is a general chemical indicator of the overall load of organic compounds in a water sample. The relative ease and non-selective nature of TOC analysis offers advantages in the context of remote spaceflight monitoring, although the disadvantage is that the analysis can't distinguish what organic chemical is contributing the TOC. Through professional judgment as to the types of compounds likely to be seen in a recycled water system, it was possible to set a health-based screening limit for TOC based on a "reasonable worst-case" compound. A TOC screening limit of 3000 parts per billion (ppb) was set by the NASA-Johnson Space Center (JSC) Toxicology Group working in conjunction with the National Research Council. The limit was established to be specific to recycled water systems, based on the assumption that a compound similar in toxicity to formaldehyde might be the entire source of the $\mathrm{TOC}^{3}$. Flight rules, hazard reports, and procedures were also established such that the recycled water from the WPA could be consumed as long as the TOC was monitored with TOCA, and TOC readings were below $3000 \mathrm{ppb}$. Consumption of water with higher TOC levels would necessitate more detailed stakeholder review and risk assessment.

From the initiation of consumption of WPA water in May of 2009, there was little cause for concern in regard to the quality of water produced by the WPA. TOC levels were consistently below the TOCA method detection limit (475 ppb) whenever the weekly TOCA sessions were completed. These mundane findings were further confirmed by returning archive water samples. In fact, some stakeholders asked if less frequent TOCA monitoring was justified given the lack of apparent issues. The irony is that the amount of data and experience gained during these nominal time periods ultimately made the events that would unfold starting in June 2010 all the more prominent and actionable. 
Figure 1: In-flight (TOCA) and Archive Water Monitoring on ISS

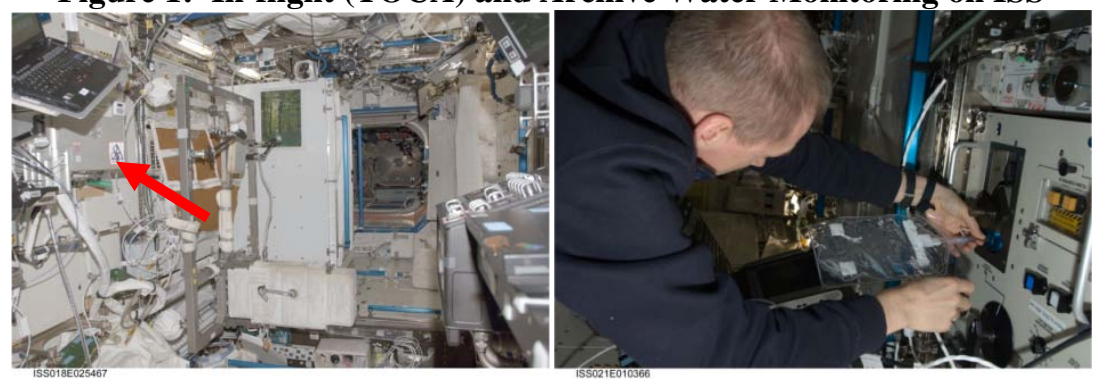

\section{B. Rise in TOC}

The first indication of a water quality change came when the TOCA recorded an unexpected TOC jump for WPA product water on June 15, 2010 (see Figure 2). JSC Space Life Sciences Directorate staff was vigilant, but recognized that the measured levels were still below the method detection limit for TOCA and were somewhat uncertain. Nevertheless, a consistent weekly rise in TOCA results quickly made it clear that this was the start of a trend. With each weekly sample, specialists watched as the TOC steadily climbed. By July, staff self-consciously joked that the "straight-line" trend charts looked almost contrived, as environmental samples rarely adhered to that type of regularity. Increasing at 100-200 ppb each week, TOC was a third of the way to the $3000 \mathrm{ppb}$ health-based limit by mid-July and half-way to this limit by Labor Day. Anomaly resolution teams were formed and fault trees were generated. Unfortunately, there would be no easy answers despite the best intended coordination. Initial data did not suggest changes in airborne volatiles on ISS that might make their way into condensate that feeds WPA. In late July, Environmental Control and Life Support Specialists (ECLSS) changed out critical multi-filtration systems, and everyone crossed their fingers, only to be disappointed by minimal impacts to the continuing upward TOC trend.

Questions were raised by some about whether the TOCA readings were accurate. After all, the internal WPA catalytic reactor health sensors that were designed to detect these types of anomalies had only responded once in early June, and were not indicating a continuing water quality challenge. Several successful TOCA calibration checks helped address these questions, although returned archive samples were really needed to verify the TOC rise and identify the chemical or chemicals that were responsible. Indeed, it was thought that many answers would ultimately be provided by the archive air, condensate, and product water samples that unfortunately remained on ISS, awaiting a late September return on Soyuz 22. Until that point, all stakeholders could really do was theorize, plan, trend, and wait.

\section{Return of the Archive Samples}

Soyuz 22 samples arrived at the WAFAL laboratory at JSC in late September 2010. Archive samples were analyzed for over 300 different chemical parameters. Analysts worked diligently to get sample results as quickly as possible given the implications for the rising TOC trend. One important initial confirmation from the ground analysis results was that TOC was indeed elevated in the WPA product water samples. While the ground analysis TOC data was approximately 25\% higher than in-flight TOCA data for the same approximate time points, this was not unexpected for a field method that must be able to address a broad array of potential TOC contributors. What was encouraging was that the archives clearly showed that TOCA served as an excellent trending tool during this event, and rises and dips in TOCA-reported TOC data could be accepted without reservation. 
Figure 2: TOC Trending in WPA product water per TOCA in 2010

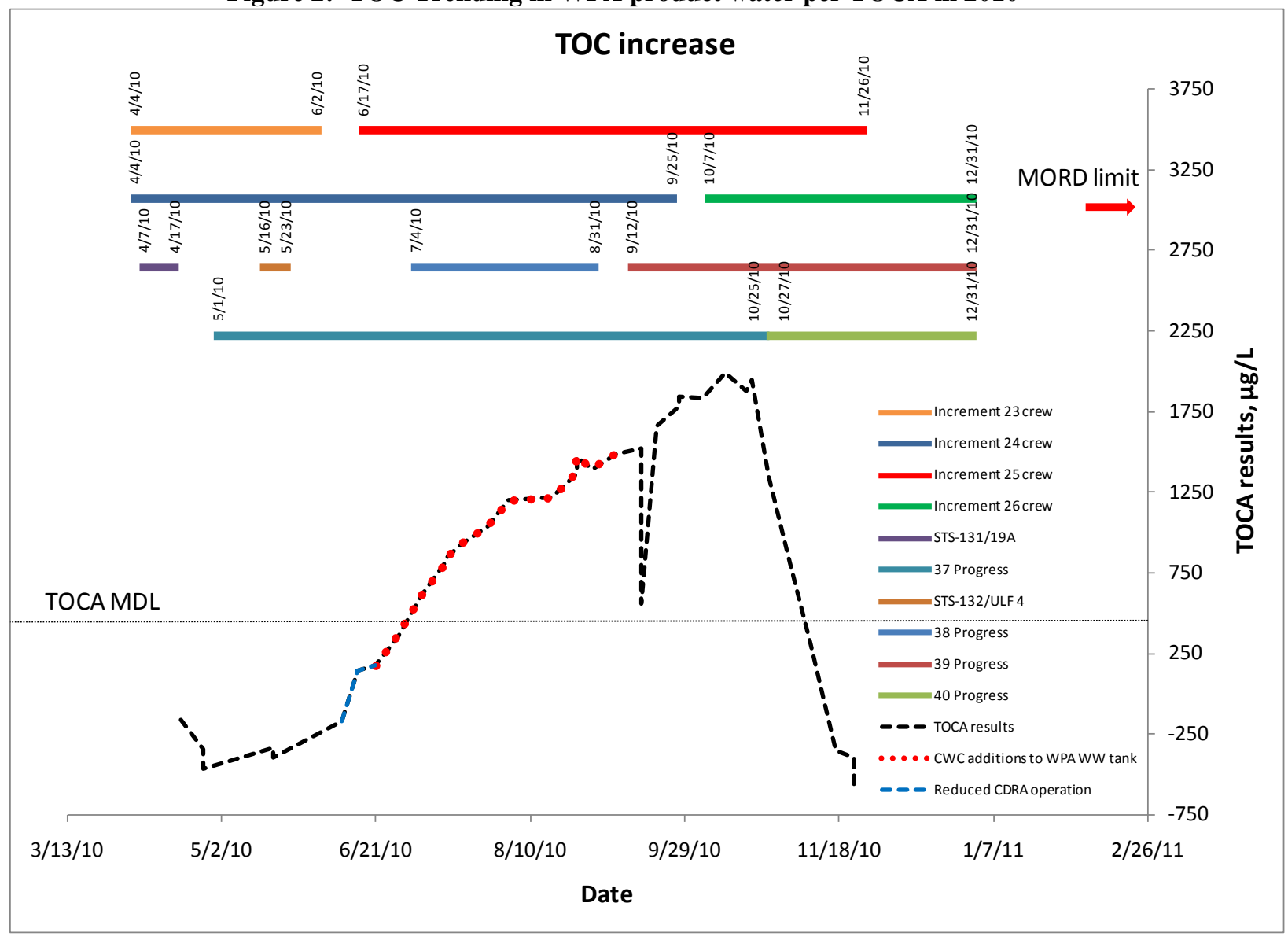

The story took an unexpected twist when the full analytical results were reviewed and no individual organic compounds were detected at significant levels in the product water. Clearly, since the TOC was verified to be high, this meant that there were non-standard analyte(s) that remained uncharacterized. Several weeks of solid analytical detective work by a number of dedicated professionals at JSC and MSFC led to the ultimate identification of the unknown as dimethylsilanediol (DMSD) ${ }^{4}$. DMSD and associated dimers were found to account for the vast majority ( $>90 \%$ ) of the TOC in the WPA product water samples (refer to Table 1 ). DMSD is a compound that is often seen as a degradation product of other silicon-based organic compounds (see Figure 3). Silicon-containing compounds (either in the form of polydimethylsiloxanes or volatile methylsiloxanes) are ubiquitous on ISS, whether as sealants, lubricating oils, or additives to a myriad of hygiene products, medications, and payloads. DMSD was found in the WPA feed water/condensate samples returned on Soyuz 22, as well as in the potable samples. One perplexing aspect was that further analysis of older (2009-2010) ISS condensate and feed water samples indicated DMSD was not a new challenge to the WPA in terms of feed water, but did not appear in prior product water samples.

Figure 3: Structure of dimethylsilanediol (DMSD)

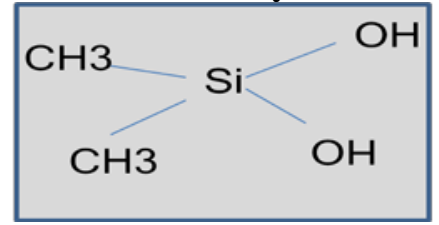

An evaluation by JSC Toxicologists concluded that oral exposures to DMSD in drinking water posed a low-tomoderate toxicological concern for spaceflight crews. Accordingly, an interim exposure limit for drinking water was set at 25,000 ppb (TOC equivalent of $6500 \mathrm{ppb}$ ). This limit was set to protect against the potential for exposure 
to DMSD to result in nervous system impairment and other adverse health effects. Fortunately, DMSD in WPA product water was reported at a maximum of $\sim 8000 \mathrm{ppb}$ (Table 1).

Now that the identity of the TOC contributor was known, practical operational planning was needed to address the reality of an elevated TOC baseline. As mentioned previously, TOCA was shown to underpredict actual TOC when the contributing compound was DMSD. In order to accurately track TOC and DMSD levels, a somewhat novel blending of in-flight and archive monitoring resources was implemented. Archive sample results were used to "baseline" known levels of TOC/DMSD for a certain date, while TOCA data were used to estimate weekly changes from that baseline. Following this approach, current TOC/DMSD levels could be accurately predicted despite the known off-set between in-flight and archive measurements (see Table 2).

Another very real concern in proceeding with operations was the potential for elevated TOCA-reported TOC to "mask" other unknown contaminants from a risk assessment perspective. In other words, the high TOC might be assumed to consist of only DMSD, whereas other organics might also be present in the product water. Unknowingly, these operational concerns were about to be mitigated through a strange twist to this story that unfolded in October of 2010.

\section{An Unexplained TOC Drop}

Given the mysterious rise in TOC/DMSD levels in June of 2010, perhaps it was fitting that it would disappear just as dramatically. From a Soyuz-returned archive sample, it is now known that a "high water mark" for TOC of $2500 \mathrm{ppb}\left(8000 \mathrm{ppb}\right.$ of DMSD) was reached around October $19^{\text {th }}$ (refer to Table 1 for a complete listing of archive TOC/DMSD levels for pertinent samples). Unexpectedly, the October $21^{\text {st }}$ in-flight TOCA reading dropped around $25 \%$ from the previous week, and successive TOCA samples recorded a similar linear decrease each week, with TOCA returning to its pre-anomaly baseline by mid November (see Figure 2). In actuality, the TOCA drop may have even occurred over a much quicker timeframe, as the three TOCA replicates performed with each sampling session became very disparate in conjunction with the TOC decline. It is theorized that quickly diminishing DMSD concentrations in conjunction with sample carryover between the weekly analyses might cause this type of analytical confounding, though recent ground testing of TOCA has not offered proof of this theory. While the rate of TOC drop may remain an unanswered question, the archive sample collected from the WPA product water on November $23^{\text {rd }}$ confirmed no detectable levels of DMSD and a return to nominal TOC levels for the first time since June 2010.

While stakeholders were obviously thrilled that the DMSD was mitigated, there was some trepidation over the fact that the root cause of both its appearance and disappearance remained unresolved. Perhaps one JSC scientist expressed these mixed feelings best in remarking, "We are really excited about the results! We just don't know why we are excited". Engineering staff had made both minor and major WPA system adjustments soon after the TOC rise was observed, and none of them had altered the consistent TOC rise to any real extent. A change in the WPA catalytic reactor temperature was made in late September, but seemingly to no avail. Only recently has evidence become available suggesting that trends in at least one silicon-containing chemical within the ISS atmosphere closely correlate with the changes observed in TOC/DMSD. The exact role of any of these factors remains an active area of investigation. As of the time of this manuscript, stakeholders are awaiting a large number of archives that will return from ISS on STS-133/ULF5. It is hoped that those samples will help fill in gaps in the story of the TOC anomaly of 2010, and will ultimately lead to a fuller understanding of the ISS environment in regard to these types of multi-disciplinary challenges.

Table 1: TOC and DMSD data from selected 2010 archive samples returned from ISS

\begin{tabular}{|c|c|c|c|}
\hline Sample & Date & TOC (ppb) & DMSD (ppb) \\
\hline WPA Product Water Sample & $7 / 14 / 2010$ & 1510 & 6100 \\
\hline WPA Product Water Sample* & $7 / 29 / 2010$ & 2180 & 7300 \\
\hline WPA Product Water Sample & $8 / 25 / 2010$ & 2190 & 8200 \\
\hline WPA Product Water Sample** & $9 / 15 / 2010$ & 1100 & 4700 \\
\hline WPA Product Water Sample & $10 / 19 / 2010$ & 2510 & 8000 \\
\hline WPA Product Water Sample & $11 / 23 / 2010$ & 150 & Not Detected $(<2000)$ \\
\hline
\end{tabular}


Table 2: Example of Approach for Integrated TOCA and Archive Data To Predict Future DMSD Levels

\begin{tabular}{|c|c|c|c|}
\hline Sample & DMSD Conc. (ppb) & TOCA Reading (ppb) & \\
\hline $\begin{array}{l}\text { PWD ambient } \\
(7 / 14 / 10)\end{array}$ & 6100 & 847 & \multirow{2}{*}{$\begin{array}{l}\text { 8/25/10 DMSD could be } \\
\text { predicted by knowing the } \\
\text { 7/14/10 archive DMSD } \\
\text { and the TOCA delta. }\end{array}$} \\
\hline PWD hot $(8 / 25 / 10)$ & ? & 1473 & \\
\hline
\end{tabular}

\begin{tabular}{|l|l|l|l|}
\hline Predicting 8/25 & archive DMSD in PWD Using Archive and TOCA \\
\hline DMSD on 7/14 & $\begin{array}{l}\text { TOCA “Delta" } \\
\text { (8/25 vs. 7/14) }\end{array}$ & $\begin{array}{l}\text { Adjustment from TOC } \\
\text { to DMSD } \\
\text { (DMSD is 26\% carbon) }\end{array}$ & $\begin{array}{l}\text { Estimated DMSD on } \\
8 / 25 / 10\end{array}$ \\
\hline $6100 \mathrm{ppb}$ & $\begin{array}{l}\text { 626 ppb } \\
\text { (1473-847 ppb) }\end{array}$ & $\begin{array}{l}\text { 2400 ppb } \\
\text { (added to 6100 ppb) }\end{array}$ & $\begin{array}{l}\text { Predicted: } 8500 \mathrm{ppb} \\
\text { **Actual: } 8200 \mathrm{ppb}\end{array}$ \\
\hline
\end{tabular}

\section{Conclusion and Lessons Learned}

While responding to the 2010 TOC anomaly was often challenging, tedious, and stressful, it also led to professional growth, greater interdisciplinary cooperation, and heightened scientific understanding of the ISS environment. Additionally, a few "lessons learned" were identified that, if heeded, might better position NASA to meet future operational challenges regarding the ISS environment.

1. Monitoring Is A Good Thing, Even if You Find Nothing.

Environmental monitoring, especially in the context of a remote and extreme environment requires major time and resource commitments. After a long time of monitoring and finding that nothing is out of the ordinary, it is quite logical to ask whether this activity is necessary at its prescribed frequency. This TOC anomaly highlighted the importance of having good insight into the environment under nominal conditions. Experience in monitoring during nominal operations allows one to more quickly separate trend from noise. It also provides context, which is crucial for influencing stakeholder opinion to act upon monitoring data when necessary.

2. Archive and In-Flight Monitoring Are Important and Complementary.

The TOC anomaly highlighted the strengths and weaknesses of both archive and in-flight monitoring, but more importantly it allowed for a demonstration of ways that the two can be used in tandem to tackle environmental challenges. Without a doubt, the TOCA proved to be a valuable and reliable screening tool that allowed us to make the right decisions regarding crew health and ISS water quality. However, despite the practical necessities (e.g., decreasing archive sample return opportunities from ISS with loss of Shuttle) and technological advancements (e.g. miniaturization) that favor the rise of in-flight techniques, it is not foreseeable that long-term crew habitation decisions can be effectively made in the total absence of archive return. It will always be important to confirm what you think you already know through full laboratory analysis of archive samples. With the TOC anomaly, even if there were in-flight techniques for all the typical compounds of concern, DMSD would have remained unaddressed. Though one might argue that, over time, system knowledge and in-flight capabilities will increase, experience tells us that there will always be something unanticipated (i.e., there will always be another DMSD).

3. Allowing for "Margin" is Critical to Success.

One aspect of the story that might be taken for granted is the amount of analytical margin (and associated response time) between the identification of the rising TOC trend and the established health-based decision point for TOC. During this period, stakeholders were able to attempt to troubleshoot and mitigate the system, return diagnostic archive samples, refine health-based standards, and develop operational plans. In part, this was fortuitous, as the TOC rise was relatively slow. An inherent rise of $1000 \mathrm{ppb} /$ week, for example, would have afforded little time for response and planning, and might have forced inaccurate and conservative decisions regarding ISS water safety. To a significant extent, however, it should be recognized 
that this margin was enabled by having a reliable in-flight monitor on-board ISS. Without this tool, minor chaos would have ensued when the archive samples returning on Soyuz showed the totally unforeseen appearance of a significant unknown. Moreover, having an in-flight instrument that was sensitive enough to detect a changing environment early-on was critical. The TOCA method detection limit (475 ppb) was a full six fold lower than the health-based screening limit of $3000 \mathrm{ppb}$. This observation should serve as a prompt to the developers of future monitoring hardware to allow for as much analytical margin as possible relative to action levels. When faced with cost trades, it is prudent to spend more development dollars to achieve operational margin. A profound truth is that it is too late to purchase response time when you find yourself in need of it.

4. Expect the Unexpected.

Consider the following observations. The WPA was thoroughly ground-tested, and was subjected to an extensive on-orbit checkout period prior to crew consumption of the water without similar incident. The TOC rise was contrary to nearly two years of nominal on-orbit operations of the WPA. The contributor to the TOC (DMSD) was not on the target analyte list for ISS. Controls inherent to the WPA (conductivity sensors) did not consistently indicate contaminant breakthrough. Finally, DMSD disappeared from potable water despite all expectations that it would continue upward. Despite the best intentions, the most comprehensive plans, the clearest fault trees, and the most logical hypotheses, the unexpected still happens. A wise response to this reality is to incorporate redundancy in designs, to plan for failures that may never occur, to be willing to expand your perspectives, and to continually seek out lessons to learn.

\section{Acknowledgments}

The authors would like to thank the multi-disciplinary team of professionals at JSC and MSFC that aided in the response to this anomaly in 2010, and who continue to work with us today to more fully understand and learn from it. Specifically worth mentioning was the work of chemists Jeff Rutz and Mike Kuo, and quality assurance coordinator Debi Plumlee with Wyle Laboratories/JSC; chemist Harold Cole with Boeing at MSFC, and MSFC ECLSS expert Layne Carter who played a strong leadership role in this story from an engineering perspective.

\section{References}

1. Straub, John E. et al. Chemical Analysis Results for Potable Water for ISS Expeditions 21-25. AIAA Technical Paper \#1021760. 41 ${ }^{\text {st }}$ International Conference on Environmental Systems, Portland, OR (July 2011).

2. Clements, Anna L. et al. Second Generation International Space Station (ISS) Total Organic Carbon Analyzer (TOCA), SAE Technical Paper \#2009-01-2393. $39^{\text {th }}$ Annual International

Conference on Environmental Systems, Savannah, Georgia (July 2009).

3. James, John T. “Total Organic Carbon”. Spacecraft Water Exposure Guidelines for Selected Contaminants, Volume 2. National Research Council, National Academies Press, 2007, pp. 453464.

4. Rutz, Jeffrey P. et al. Discovery and Identification of Dimethylsilanediol as a Contaminant in ISS Potable Water. AIAA Technical Paper \#1021758. 41 ${ }^{\text {st }}$ International Conference on Environmental Systems, Portland, OR (July 2011). 